TAPROBANICA, ISSN 1800-427X. January, 2015. Vol. 07, No. 01: pp. 8-13, pls. 4-8.

(C) Research Center for Climate Change, University of Indonesia, Depok, Indonesia \& Taprobanica Private Limited, Homagama, Sri Lanka

www.taprobanica.org

\title{
DISPLAY BEHAVIOUR OF INDIAN PEAFOWL Pavo cristatus (AVES: GALLIFORMES) DURING THE MATING SEASON IN VIRALIMALAI, TAMILNADU, INDIA
}

Varadharajan Gokula $^{1,2}$ and V. Muthukrishnan ${ }^{1}$

\footnotetext{
${ }^{1}$ Post Graduate \& Research Department of Zoology, National College, Tiruchirappalli 620001, Tamil Nadu, India; E-mail: gokulae@yahoo.com ${ }^{2}$
}

\begin{abstract}
The Indian peafowl (Pavo cristatus), the largest of the pheasants in India, inhabits mostly semi-arid conditions. We examined the courtship displays of free-ranging peacocks in relation to the orientation and the relative positions of females being courted from August 2012 to January 2013 in Viralimalai, Tamil Nadu, India, to address these questions: (1) Do the peacocks orient their courtship display towards the sun? (2) Is there any relationship between the presence of peahen and the duration of display of peacock? (3) Is there any site-preference to display? We found that the majority of the displays were oriented towards the sun initially, but then oriented towards peahen (regardless of direction) soon after their arrival. Although peacock displayed even in the absence of peahen, presence of peahen influenced the display duration of peacock. Displays were performed largely in open areas.
\end{abstract}

Keywords: courtship, orientation, peahen, pheasants, semi-arid habitats, South India.

\section{Introduction}

The Indian peafowl (Pavo cristatus) is widely distributed in the semi-arid habitats of India (Dharmakumarsinhji \& Lavkumar, 1981; Ali \& Ripley 1983). It is protected throughout India, especially under Schedule-I of the Indian Wildlife Protection Act, 1972, and its subsequent amendment and Appendix-1 of CITES (Dodia, 2011). At present, it is found in parts of West Bengal, Bihar, Orissa and Peninsular India, but with most abundant numbers in the states of Gujarat and Rajasthan.
However, very little published information is available on this species in India. Sharma (1978), Sathyanarayana \& Rathinasabapathy (1990, 1992), Yasmin (1995), and Dodia (2011) reported the ecological aspects of peafowl. Gadagkar (2005) and Yasmin \& Yahya (1996) studied their communication signals, evolution, and social organisation. Very recently, Ramesh \& McGowan (2009) reported the current status of the peafowl in India. The elaborate train of the male Indian peafowl and its display is a 
visual signal, directed at females, and has long been a subject of debate in the scientific world (Harikrishnan et al., 2010). It is often used as a model for the study of animal signals and their evolution (Gadagkar, 2003). Several experimental and observational studies on captive populations of the Indian peafowl have advanced our understanding of the selection of ornamentation in males (Manning, 1989; Petrie et al., 1991, 1992; Petrie, 1992; Petrie \& Halliday, 1994; Petrie et al., 1996, 1999). The available evidence indicates that the train of the male Indian peafowl could be expensive in terms of time spent in its maintenance (Walther \& Clayton, 2005).

In the present study, we examined the displays of free-ranging peacocks in relation to the orientation and relative positions of females being courted from August 2012 to January 2013 in Viralimalai, Tamil Nadu, India. The following questions were addressed: (1) Do peacocks orient their courtship display towards the sun? (2) Is there any relationship between the presence of peahen and the duration of courtship displays of peacock? (3) Is there any site-preference for display?

\section{Materials and Methods}

Study area: Viralimalai is situated between $10^{\circ} 36^{\prime} 6^{\prime \prime} \mathrm{N}$ and $78^{\circ} 32^{\prime} 47^{\prime \prime} \mathrm{E}$ (Fig. 1). The terrain is generally flat with dry open lands with cultivation, as well as semi-barren wastelands. The scrub jungle, once plentiful, is now left in a few fragments due to anthropogenic pressure. Tanks, called kanmai in Tamil, irrigate the existing agricultural fields and are ubiquitous irrespective of geology.

The study area has a hot tropical climate. The summer season is from March to May, with May being the hottest (average $37{ }^{\circ} \mathrm{C}$ ). Southwest monsoon lasts from June to August. The northeast monsoon lasts from October to December and brings considerable rain to this area. The relative humidity is between 50 and 80 per cent, but during February to July the air is drier. The annual rainfall is $950 \mathrm{~mm}$. The sky is generally cloudy during the monsoon. In the rest of the year it is mostly clear. Though agriculture is the main source of sustenance for a majority of the human population, the predominant dry land farming suffers badly due to frequent poor monsoons affecting agricultural production.
Data collection and analysis: The breeding season of the Indian peafowl is closely related to the monsoons; therefore, the timing in the year varies according to locality (Johnsingh \& Murali, 1980). In our study area, displaying by males started in October and continued until the first week of December which corresponds to the northeast monsoon. Individuals of Indian peafowl were classified into three categories (adult males, sub-adult males and females) following the classification of Johnsgard (1986); however, we combined the first and second year males as sub-adults due to possible errors in assigning individuals to these two categories. We used the term "display court" as defined by Armstrong (1947) to describe the site used by an adult male during display (i.e., a small area that was defended by an adult male from other males and was used for keeping vigil and displaying). Searches were made for displaying peacocks from $0530 \mathrm{~h}$ to $1930 \mathrm{~h}$. Once a display was found, the display behaviour was observed from start to finish using instantaneous sampling (Dakin \& Montgomerie 2009). For each bout, we recorded the time and the identity of the male, as well as the following variables: total time spent on display, train rattling, wing shaking, number of rotations made during the entire display period, orientation of the display (including any changes during the entire display), presence of female and their position around the displaying male. The location of a target female was recorded as being in one of the six $\left(60^{\circ}\right)$ sectors around the male (Fig. 2) following Dakin \& Montgomerie (2009) Behavioural observations were made at display courts that were most readily visible from a chosen vantage position, situated $50 \mathrm{~m}$ away from the closest displaying male. A total of 151 displays performed by 151 adult males (with an assumption that all the adults maintain individual leks) at 151 different sites were used for the present study conducted between August 2012 and January 2013. In order to avoid any particular adult males' influence, displays found more than once in the same place was not included. Chi square test was performed to test whether peacocks show any preference in the display orientation and display area between morning and afternoon. Pearson correlation was performed to determine whether there was a significant relationship between the presence of peahen and the duration of courtship display by peacock. Statistics were performed using PAST software (Hammer et al., 2001). 


\section{Results and Discussion}

Peacocks (genus Pavo) are known for their highly elaborate train feathers displayed during courtship and assessed by females during mate choice (Darwin, 1871; Petrie et al., 1991; Petrie \& Haltiday, 1994; Loyan et al., 2005, 2007a,b; Takahashi et al., 2008; Dakin \& Montgomerie, 2011). The iridescent train of the peacock is an obvious visual display, long thought to be the result of sexual selection for increased ornament size and complexity (Darwin, 1871). The available evidence indicates that the train of the male Indian peafowl could be expensive in terms of time spent in its maintenance (Walter \& Clayton, 2005). We found that the majority of the 151 males studied maintained a single display court throughout the breeding season. However, courts of two individuals were seen and usually separated by $>20 \mathrm{~m}$, but in a few cases there was a 2 to $5 \mathrm{~m}$ distance between two courts. Indian peafowl are reported to be polygynous (Ali \& Ripley 1969) and polyandrous (Lanket et al., 2002) and have a "lek" like mating system where males defend small and clumped territories (Lanket et al., 2002; Rands et al., 1984; Loyau, 2007a,b). Availability of undisturbed sites to display in the anthropogenic ecosystem may be one of the key factors that determine the distance between the leks.

Of the 151 displays, it was found that majority were in the early and late hours of the day (Fig. $3)$. No displays were recorded during the hottest hours of the day (12:00 h to 15:00 h). Displays were recorded after sunset when females were present. However, displays began only after sunrise even without the presence of females. Displays were more frequent during the morning than afternoon. Petrie et al., (1991) and Walther (2003) found feral peacocks display during morning and late afternoon. The behaviour of an animal is strongly influenced by age and sex. In the present case, male incur "high maintenance and handicap" and thus performing displays in the absence of females or in the hottest hours of the day would certainly not be an energy conserving strategy. Hence, performing the energy consuming behaviour in the early and late evening hours of the day would certainly be beneficial to the animal that performs the activity. Moreover, females were also less active in the hottest hours of the day and performing in the midday often minimizes the reflecting value of iridescent plumage towards the target female as the sun is directly above the displaying animal. On the other hand, perfect angular light during the morning and evening maximize the reflecting value of iridescent plumage towards the target female.

Of the 151 displays, duration varied from $1 \mathrm{~min}$ to $31.2 \mathrm{~min}$ (Fig. 4). Although some displays were recorded for more than half an hour, most of the displays were recorded for 1-2 min. The majority of the displays were started without any female in the vicinity. Once an adult started displaying, nearby adults (if any in the vicinity) were restless until they too started displaying. Even sub-adults showed this same behaviour despite their lack of a train. The male first squats and rises suddenly to start displaying. Displaying males were very aggressive towards sub-adult males if present in the vicinity: often a male would make a forward lunge directed at the sub-adult. Once the sub-adult moved some distance away from the displaying male, the adult male ignored him. The sub-adult simply continued its display at this point. Reduced feeding and increased display and maintenance activities are energetically costly for a male, and therefore, ensure that only the fittest males are able to display for long periods of time resulting in greater mating success.

The majority of males displayed towards the east in the morning and the west in the afternoon (Fig. 5). Orientation of display differed significantly between morning and afternoon $\left(\chi^{2}\right.$ $=8.330$, $\mathrm{df}=3, p=0.04)$. However, direct sunlight on the front side of the trains was not often sighted. Similarly, once the females entered the vicinity, males changed their orientation according to the position of the female. A minimum of 0.5 to a maximum of 28 rotations were made by the displaying males. The maximum number of rotations were recorded when display duration was maximum (Fig. 6). However, one average one to three rotations were recorded in displays.

During the display time, calls were infrequently made. A maximum of six calls were made only once while $>30$ displays went without any calls (Fig. 7). Calls were generally made very loud, sharp and repeated five to six times in quick succession in non-display hours. However, while in display, calls were not in succession but often with gaps. Calls during display were of "mayawe" type, often made at the beginning of the 
display and rarely during the middle and late display. Harikrishnan et al., (2010) also reported such successive calls but failed to report the details of calls during the display. We infer that like display, calling may also be expensive, and thus performing both the expensive behaviours together may not be advantageous.

Although the majority of the displays started without the presence of female, the female arrived to the spot soon. The majority of the females approached the displaying males from the back and gradually moved towards various positions in front of the male irrespective of time of day (Fig. 8-11). Regardless of time of day, females approached the male initially between an angle of $180^{\circ}$ to $300^{\circ}$ and then took a position anywhere from $0^{\circ}$ to $120^{\circ}$. Dakin \& Mongomerie (2009) also reported a similar pattern in their study.

Displays were made on the ground, top of buildings, inside wells, and on the bund around the wells (Fig. 12). The courts were typically slightly elevated, similar to a mound, fallen tree, or large rock, and adult males stood on these and kept vigil on approaching females. The top of the roof was the highest point was males were seen. On a few occasions, displays were made inside the well around the time of the peahen arriving for drinking water. Harikrishnan et al. (2010) also reported such displays on elevated sites in the wooded countries. Displays were made both in open and shaded areas. Although number of courtship displays performed by peacocks in open and shaded areas did not differ significantly in the morning, it differed significantly in the afternoon $\left(\chi^{2}=26.06, \mathrm{df}=1\right.$, $\mathrm{p}=0.00)$. Though not significant, more courtship displays were recorded in open areas (Fig. 13). Display area significantly differed between morning and afternoon $\left(\chi^{2}=27.615\right.$, df $=1, \mathrm{p}=0.05)$. Open areas provided various opportunities to effectively perform displays as they allowed for attracting females from a longer distance and vigilance over females, sub-adults, humans, and other disturbances. In general, display court selection most likely involves a number of factors, including proximity to food resources where female congregate (Loyau et al., 2007a,b), proximity to closely related males (Petrie et al., 1999), distance from agnostic males and predators, and shelter from the wind.
Of the 151 displays, only 49 were performed in the presence of females. In 46 of the 49 displays, females approached the males soon after the display started. Display duration significantly increased as the time of presence of females increased $(r=0.312, \mathrm{p}=0.02)$. Although train rattling was observed even without the presence of females, males rattled their train largely when the females were in position $2\left(60^{\circ}-120^{\circ}\right)$. However, no such pattern was obvious in the case of wing shaking: it was observed both in the presence and absence of females. Of the 102 displays when males could not attract any females, display duration varied from $0.05 \mathrm{~min}$ to almost $12 \mathrm{~min}$. However, in the presence of females, display duration varied from $50 \mathrm{sec}$ to 31.2 min. Dakin \& Montgomerie (2009) also observed the similar pattern. In general, it may be inferred that train rattling, wing shaking, and rotation while display do influence the peahen choice rather than just orienting the display towards the sun to maximize the reflective value of iridescent plumage. The reflective value of the iridescent plumage may be maximized by rotating, rattling and shaking movements with minimum light when peahen is nearby rather than orienting the display towards the sun.

\section{Acknowledgement}

We thank the Principal and the Management of National College, Tiruchirappalli for their support.

\section{Literature cited}

Ali, S. and D. S. Ripley, 1969. Handbook of the birds of India and Pakistan. Oxford University Press: UK.

Ali, S. and D. S. Ripley, 1983. Handbook of the Birds of India and Pakistan, Compact. Edition, Oxford University Press, Mumbai.

Armstrong, A. A., 1947. Bird display and behaviour: an introduction to the study of bird psychology. England: Lindsay Drummond Ltd.

Dakin, R., and R. Montgomerie, 2009. Peacocks orient their courtship displays towards the sun. Behavioural Ecology \& Socio-biology, 63: 825834.

Darwin, C., 1871. The descent of man, and selection in relation to sex. $1^{\text {st }}$ edition. John Murray, London, UK. 
Dharmakumarsinhji, R. S. and K. S. Lavkumar, 1981. Indian peafowl, sixteen Indian birds. Publication division, Ministry of information and broadcasting, Government of India: 24-28.

Dodia, P. P., 2011. Roost Tree Selection by The Common Indian Peafowl Pavo cristastus at Bhavnagar District, Gujarat (India). Life sciences Leaflets, 11: 346-354.

Gadagkar, R., 2003. Is the peacock merely beautiful or also honest? Current Science, 85: 1012-20.

Johnsgard, P. A., 1986. The Pheasants of the world. Oxford: Oxford University Press.

Johnsingh, A. J. T., and S. Murali, 1980. The ecology and behavior of Indian peafowl Pavo cristatus Linn. Journal of Bombay Natural History Society, 75: 1069-79.

Hammer, Ø., D. A. T. Harper, and P. D. Ryan, 2001. PAST: Paleontological Statistics Software Package for Education and Data Analysis. Palaeontologia Electronica, 4: 1-9.

Harikrishnan, S., K. Vasudevan, and K. Sivakumar, 2010. Behaviour of Indian Peafowl Pavo cristatus Linn. 1758. during the mating period in a natural population. The open ornithology, 3: 13-19.

Lanket, D. B., C. M Smith, O. Hanotte, A. Ohtonen, S. Bailey, and T. Burke, 2002. High frequency polyandry in a lek mating system. Behavioural Ecology, 13: 209-15.

Loyau, A., D. Gomez, B. Moureau, M. Théry, N. S. Hart, M. Saint Jalme, A. T. D. Bennett, and G. Sorci, 2007a. Iridescent structurally based coloration of eyespots correlates with mating success in the peacock. Behavioural Ecology, 18: 1123-1131.

Loyau, A., M. Saint Jalme, and G. Sorci, 2005. Intra- and inter-sexual selection for multiple traits in the peacock Pavo cristatus. Ethology, 111: 810 820 .

Loyau, A., M. Saint Jalme, and G. Sorci, 2007b. Non-defendable resources affect peafowl lek organization: a male removal experiment. Behavioral Processes, 74: 64-70.
Manning, J. T., 1989. Age-advertisement and the evolution of the peacock's train. Journal of Evolutionary Biology, 2: 379-84.

Petrie, M., 1992. Peacocks with low mating success are more likely to suffer predation. Animal Behaviour, 44: 585-6.

Petrie, M., 1994. Improved growth and survival of offspring of peacocks with more elaborate trains. Nature, 371: 598-9.

Petrie, M. and T. Halliday, 1994. Experimental and natural changes in the peacock's Pavo cristatus train can affect mating success. Behavioural Ecology and Socio-biology, 35: 213-217.

Petrie, M., P. Cotgreave, and I. Stewart, 1996. Variation in the train morphology of the peacocks. Journal of Zoology, 238: 365-71.

Petrie, M., T. Halliday, and C. Sanders, 1991. Peahens prefer peacocks with elaborate trains. Animal Behaviour, 41: 323-331.

Petrie, M., A. Krupa, and T. Burke, 1999. Peacocks lek with relatives even in the absence of social and environmental cues. Nature, 401: 155157.

Petrie, M., M. Hall, T. Halliday, H. Budgey, and C. Pierpoint, 1992. Multiple mating in a lekking bird: why do peahens mate with more than one male and with the same male more than once? Behavioural Ecology and Socio-biology, 31: 1-10.

Ramesh, K. and P. McGowan, 2009. On the current status of Indian Peafowl pavo cristatus (Aves: Galliformes: Phasianidae): keeping the common species common. Journal of Threatened Taxa, 1: 106-108.

Rands, M. R. W, M. W. Ridley, A. D. Leliott, 1984. The social organization of feral peafowl. Animal Behaviour, 32: 830-5.

Sathyanarayana, M. C. and B. Rathinasabapathy, 1990-92. Notes on the feeding ecology and activity patterns of the blue peafowl. Journal of World Pheasant Association, 15 \& 16: 97-101.

Sharma, I. K., 1978. Social and sexual behavior of peafowl. Environmental Awareness, 1: 169-71. 
Takahashi, M., H. Arita, M. Hiraiwa-Hasegawa, and T. Hasegawa, 2008. Peahens do not prefer peacocks with more elaborate trains. Animal Behaviour, 75: 1209-1219.

Walther, B. A., 2003. Do peacocks devote maintenance time to their ornamental plumage? Time budget of male blue peafowl Pavo cristatus. Lundiana, 4: 149-154.

Walther, B. A. and D. A. Clayton, 2005. Elaborate ornaments are costly to maintain: evidence for high maintenance handicaps. Behavioural Ecology, 16: 89-95.

Yasmin, S., 1995. Roost tree characteristics of Indian Peafowl, WPA Annual Review, 1:57-63.

Yasmin, S. and H. S. A. Yahya, 1996. Correlates of mating success in Indian peafowl. Auk, 113: 490-492. 


\section{PLATE 4}

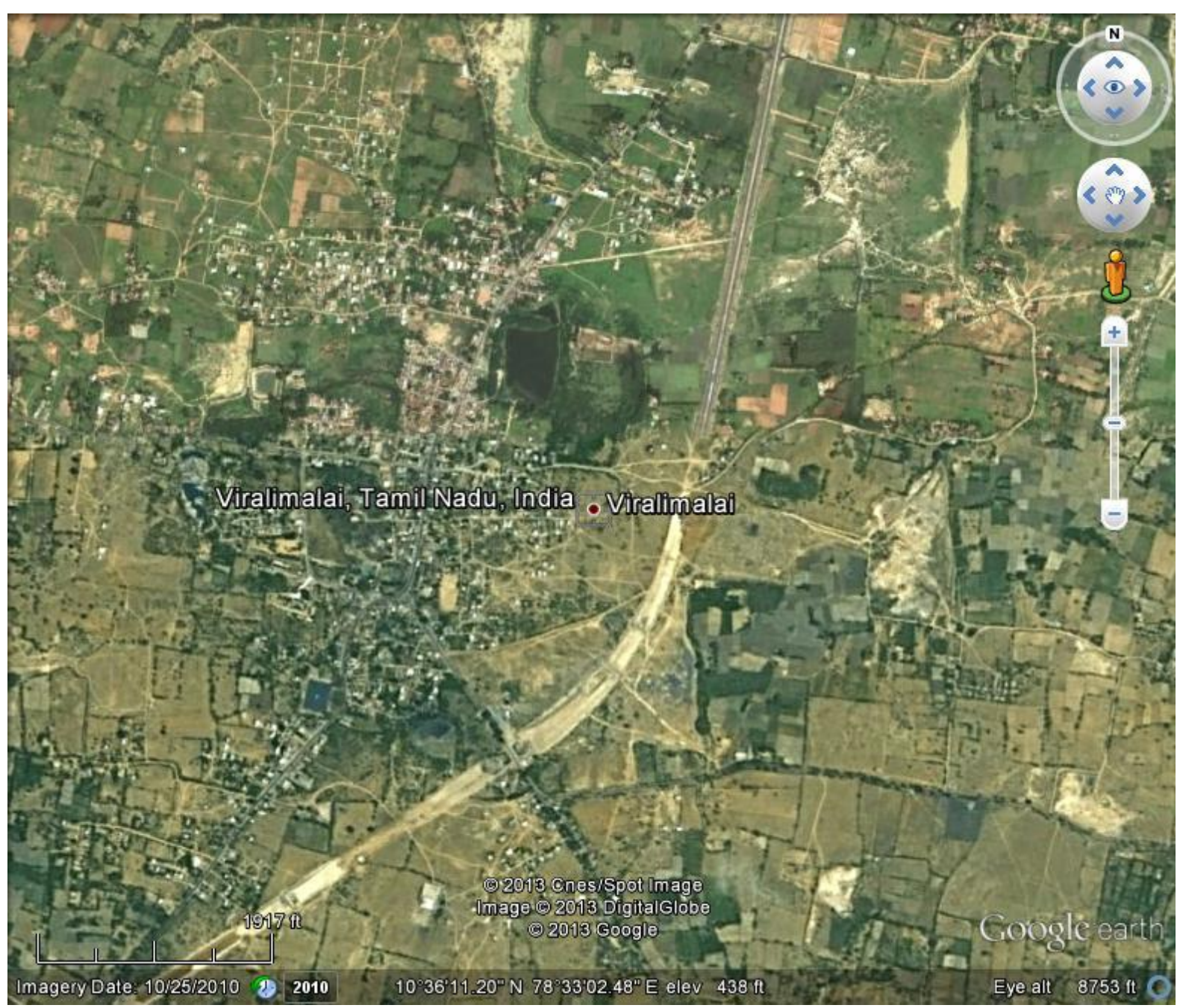

Figure 1: Map showing the study area

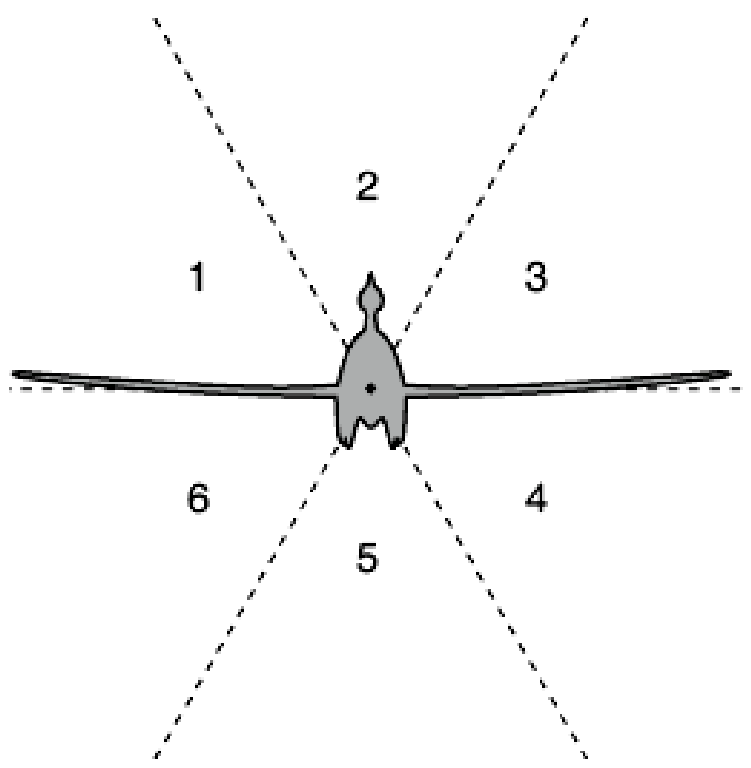

Figure 2: Positions of females found during the display used for the present study. 


\section{PLATE 5}

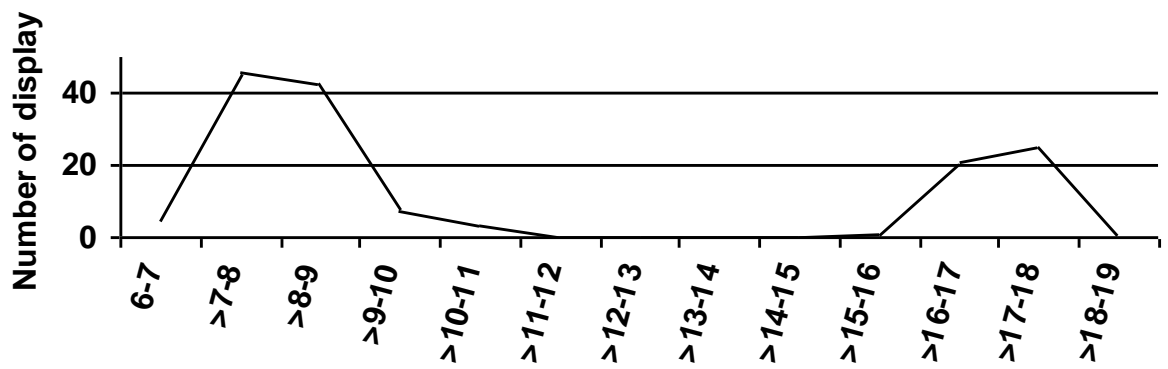

Hours of the Day

Figure 3: Frequency of courtship display of peacock recorded during various hours of the day $(n=151)$

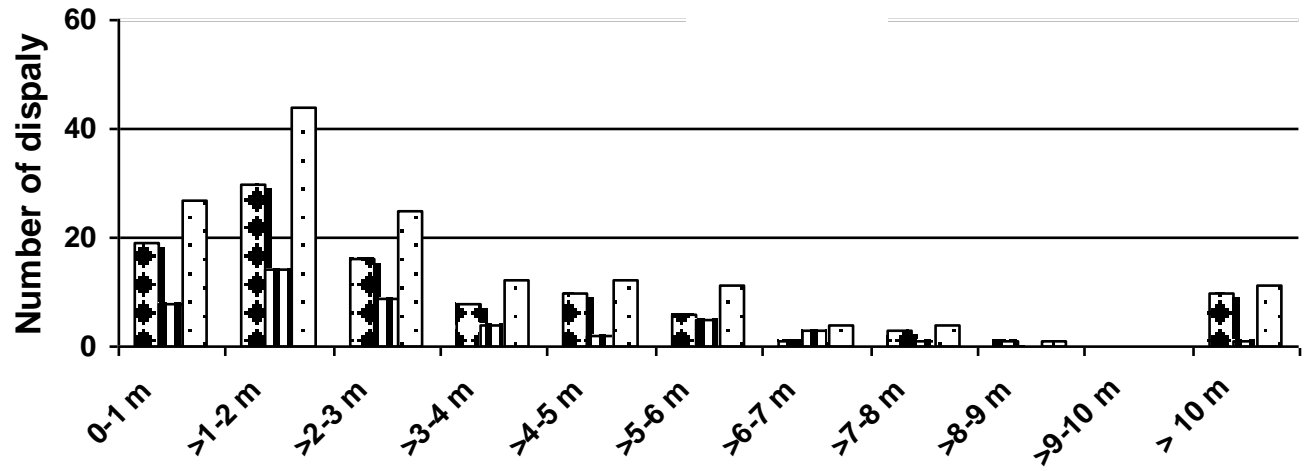

Display duration in minutes

$\varpi$ Morning $\mathbf{\square}$ Evening $\square$ Overall

Figure 4: Duration of courtship display of peacock in Viralimamai $(n=151)$

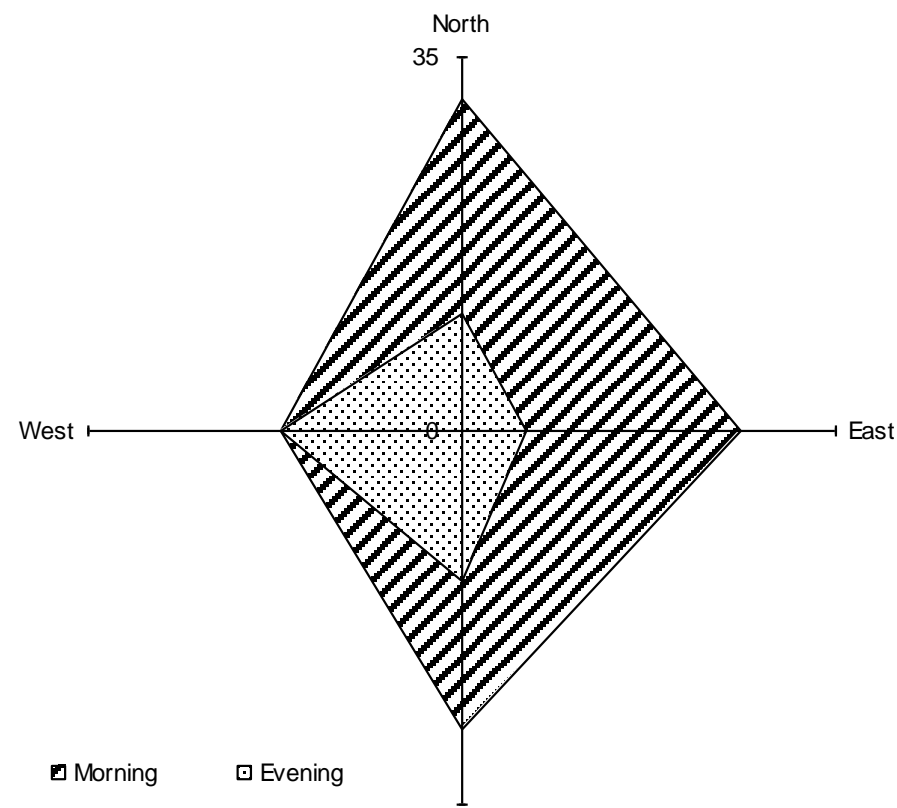

Figure 5: Orientation of courtship display of peacock in Viralimalai 


\section{PLATE 6}

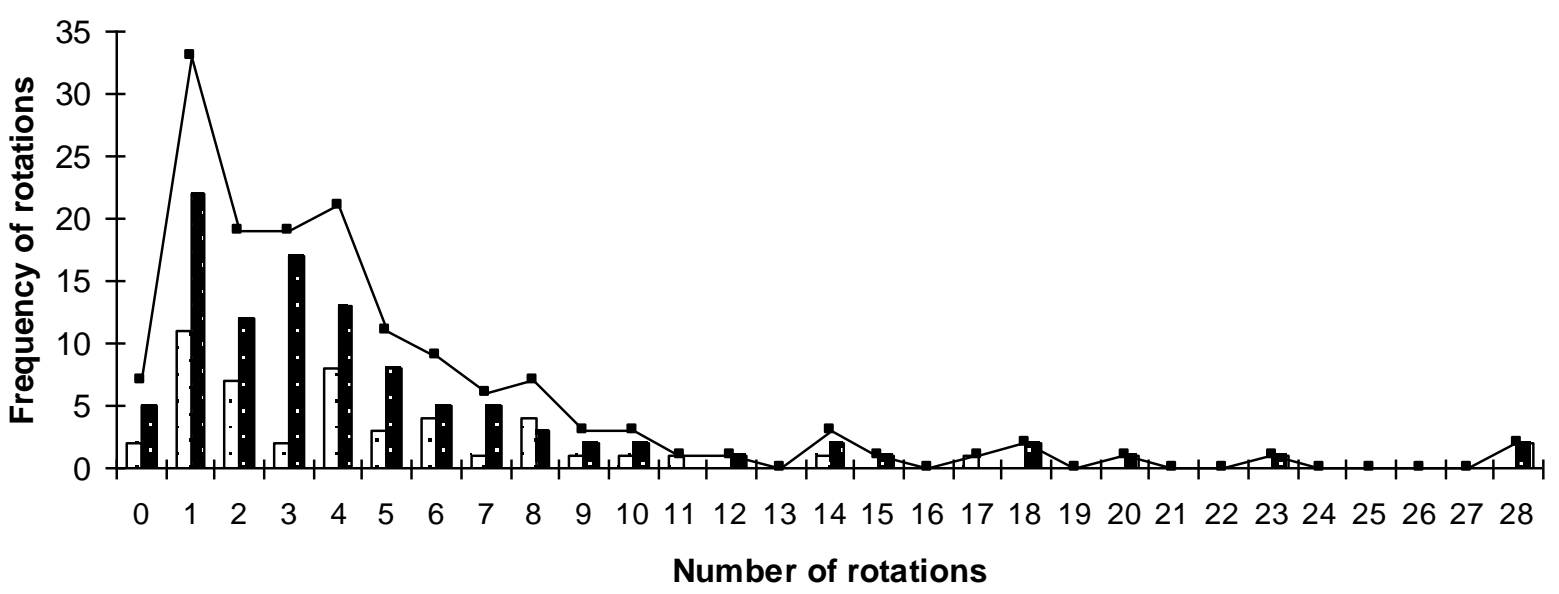

$\varpi$ evening $\rightarrow$ morning $\rightarrow$ Overall

Figure 6: Frequency of rotations made during courtship display by peacock in Viralimalai

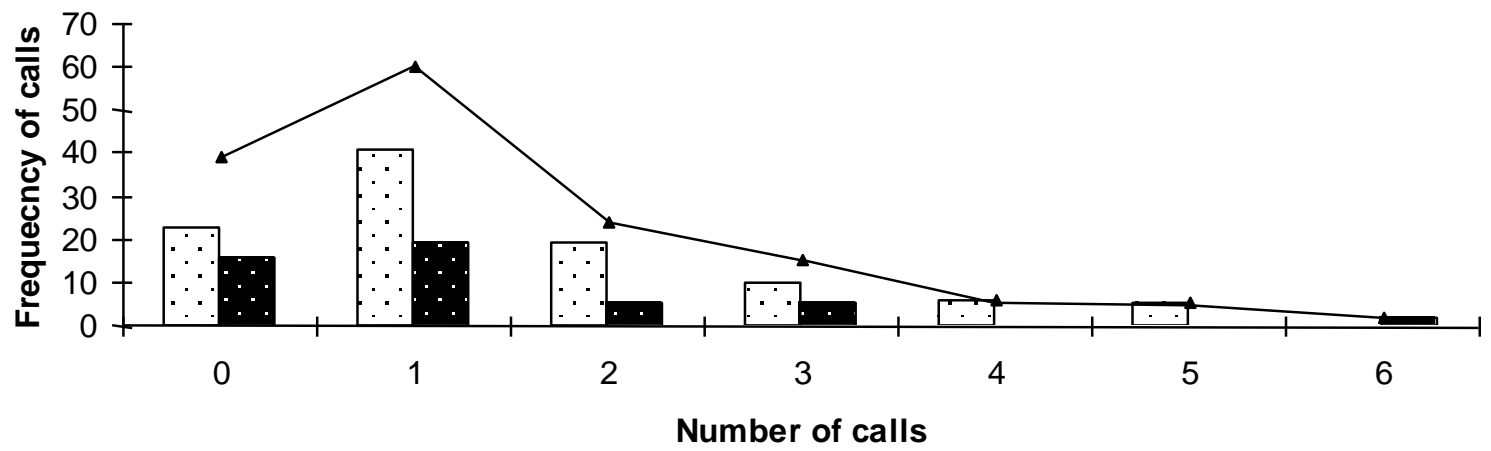

$\varpi$ morning $\curvearrowleft$ evening $\multimap$ overall

Figure 7: Calls made by peacock during courtship display

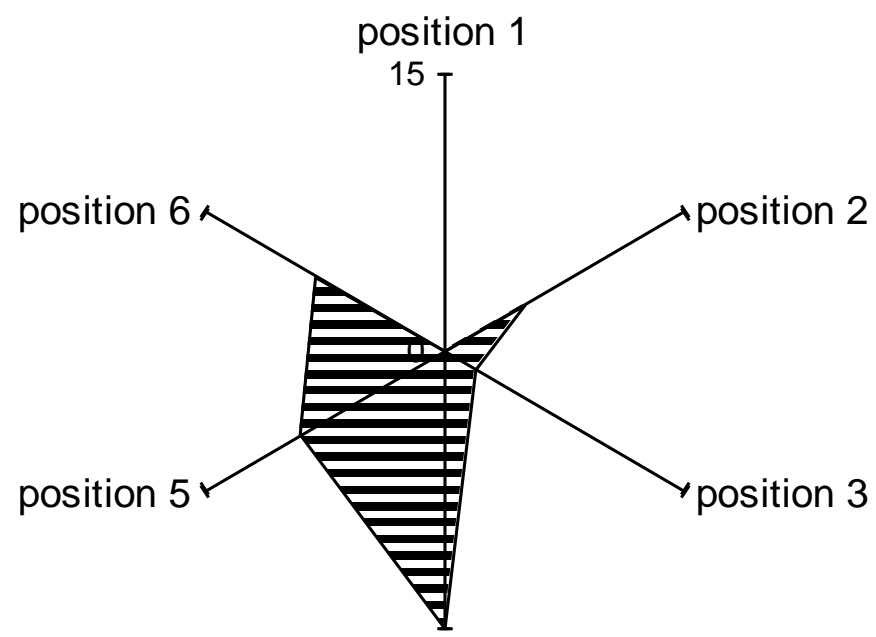

position 4

Figure 8: Position of the peahen (adult) during the initial period of the peacock's display (afternoon hours) 


\section{PLATE 7}

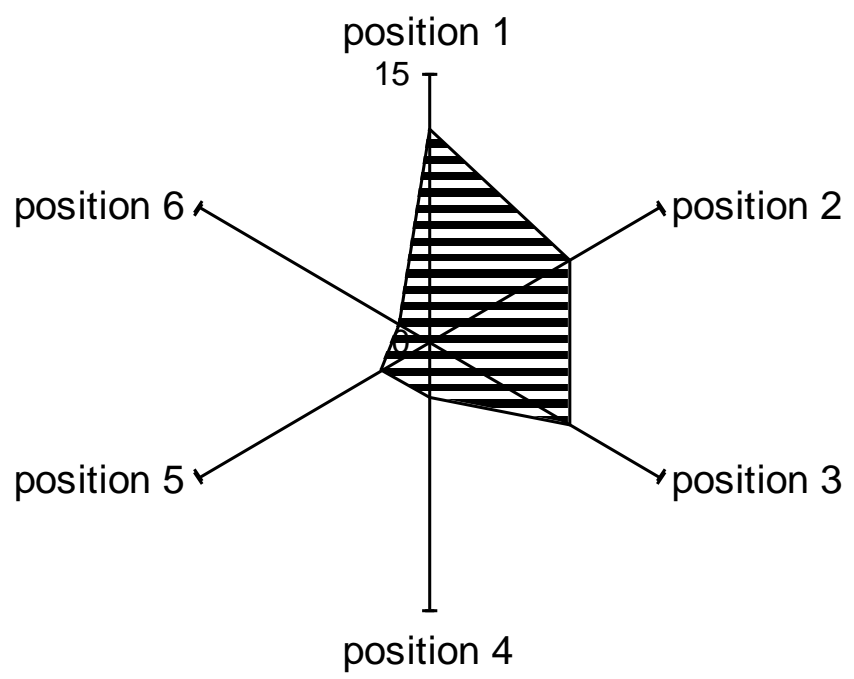

Figure 9: Position of the peahen (adult) during the end period of the peacock's display (afternoon hours)

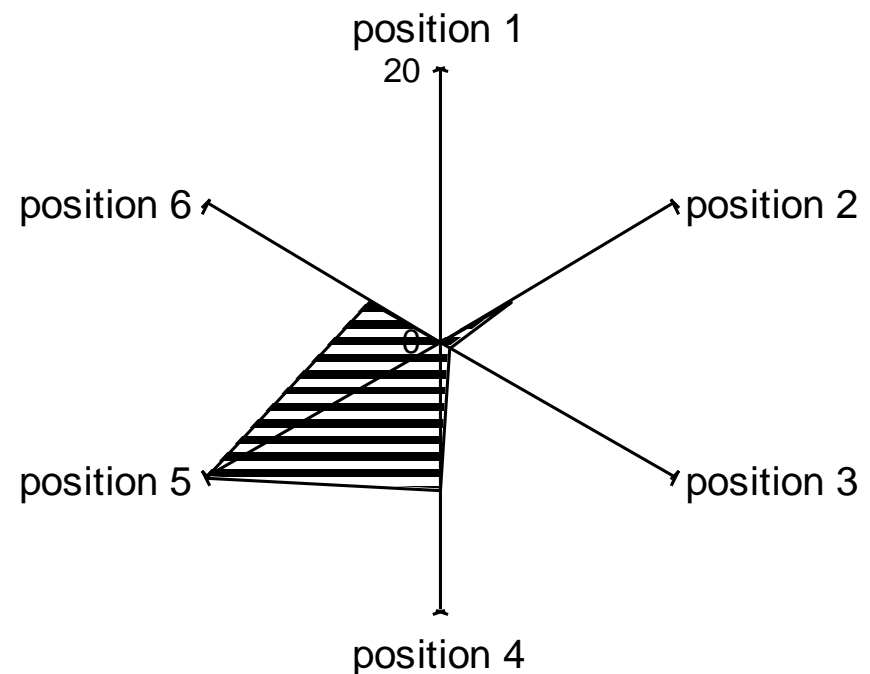

Figure 10: Position of the peahen (adult) during the initial period of the peacock's display (forenoon hours)

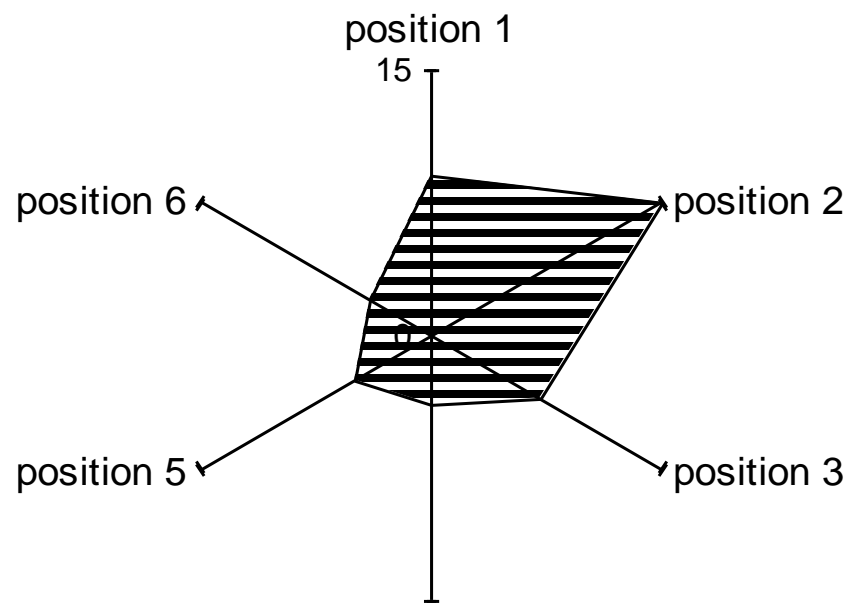

position 4

Figure 11: Position of the peahen (adult) during the end period of the peacock's display (forenoon hours) 


\section{PLATE 8}

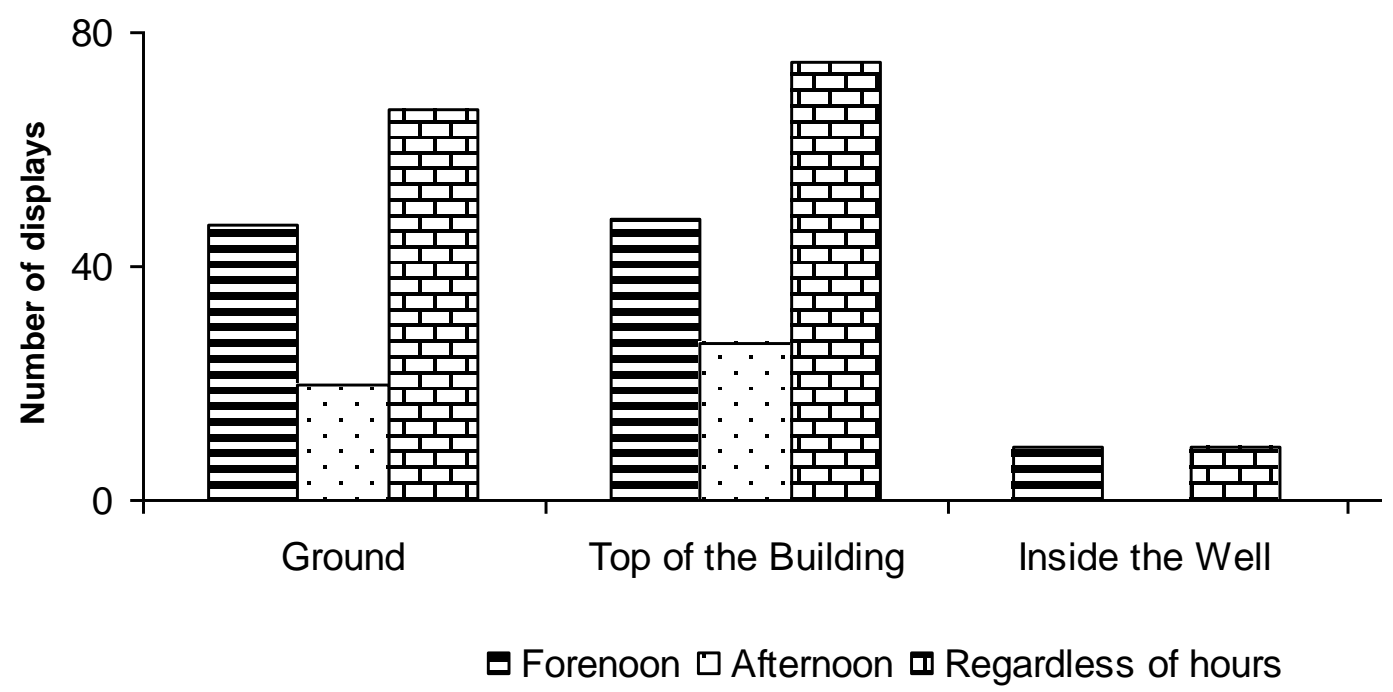

Figure 12: Frequency of peacock's display recorded at various sites in Viralimalai

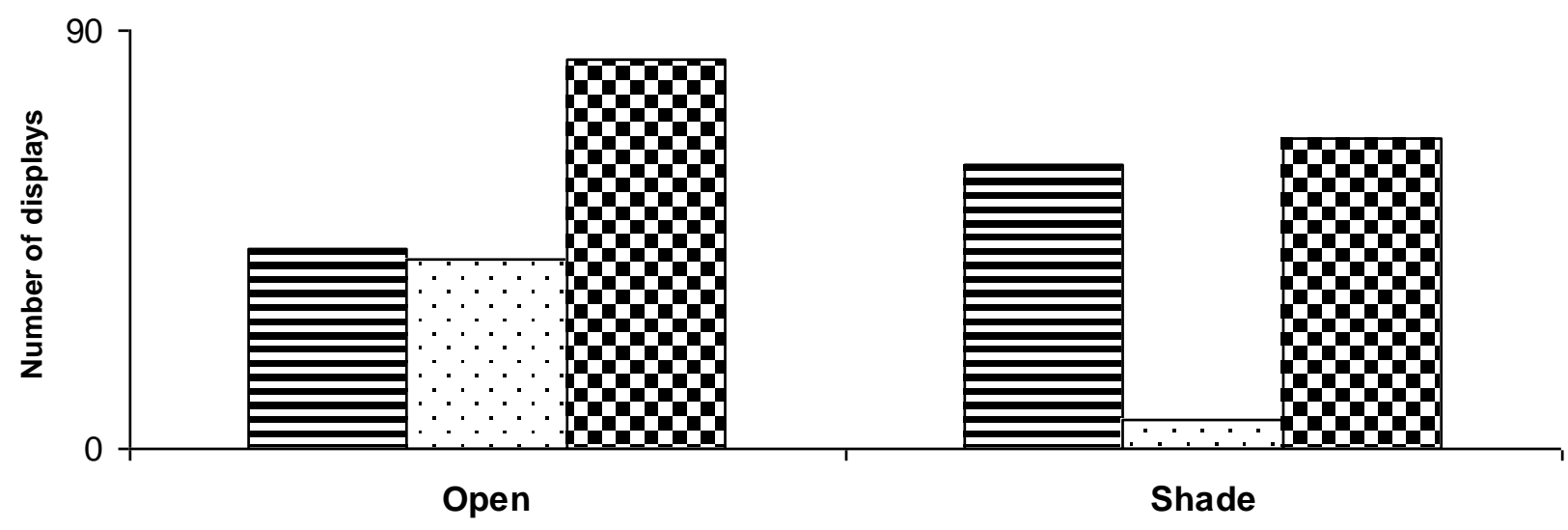

E Forenoon $\square$ Afternoon $\square$ Regardless of hours

Figure 13: Frequency of peacock's display recorded in open and shaded areas at Viralimalai 